\title{
Motives Behind The Integration Of CSR Into Business Strategy: A Comparative Study In French SMEs
}

Linh-Chi Vo, Ecole de Management de Normandie, France

Karen Delchet-Cochet, ISC Paris Business School, France

Hakim Akeb, ISC Paris Business School, France

\begin{abstract}
Corporate social responsibility (CSR) in the context of small and medium enterprises (SMEs) has become an important and substantial area of study for quite a few years. In this literature, while so much research has shed light on what makes SMEs integrate CSR into their business strategy, the existing results regarding their economic, social, and environmental motives are contradictory. In this article, we aim at making a contribution by conducting an integrative study. More specifically, we compare the roles of economic, social, and environmental motives in driving SMEs to make CSR become an integral part of their strategic planning and routine operational performance. Our sample includes 155 French SMEs.
\end{abstract}

Keywords: SMEs; CSR; Economic Motive; Social Motive; Environmental Motive

\section{INTRODUCTION}



orporate social responsibility (CSR) in the context of small and medium enterprises (SMEs) has become an important and substantial area of study for quite a few years. This topic has attracted a considerable number of dedicated scholars and has also been the subject of two special issues in Journal of Business Ethics (Vol. 47, No. 1, 2003; Vol. 67, No. 3, 2006), and a special issue in Business Ethics: a European review (Vol. 18 , No. 1, 2009). An important topic in this literature is related to the drivers of the integration of CSR in SMEs' business strategy, which is triggered by the general argument that CSR can bring competitive advantage (Porter \& Kramer, 2002). While so much research has shed light on what make the SMEs integrate CSR into their business strategy, the existing results regarding their economic, social, and environmental motives are contradictory.

On the one hand, it has been shown that SMEs integrate CSR into their business strategy in order to improve their financial performance (e.g. Fisher et al., 2009; Longo, Mura, and Bonoli, 2005; Murillo and Lozano, 2006). In many cases, SMEs emphasize economic survival over voluntary social and environmental initiatives (Lepoutre and Heene, 2006; Tilley, 1999; Jenkins, 2004); the economic motive is the most important driver of CSR integration into business strategy. On the other hand, it has been argued that due to the owner-centric characteristics of SMEs, they integrate CSR into business strategy primarily for social and environmental motives. CSR is important to them because it is simply the 'right thing to do' (Jenkins, 2006). With their strong 'green attitude' (Gadenne, Kennedy, and McKeiver, 2009) and their particularly close relationship with the local community (Longo, Mura, and Bonoli, 2005), economic motive plays a less important role than the social and environmental ones in driving the integration of CSR into their business strategy.

In this article, we contribute to the literature by comparing the roles of economic, social, and environmental motives in driving SMEs to integrate CSR into their business strategy. We thereby make several contributions to the literature. First, our work responds to the call for further empirical investigation about the concurrence of ethical and strategic interests in SMEs' CSR agenda (Morsing and Perrini, 2009). Second, it also brings insight about the most important factors driving a strategic CSR behavior among SMEs. 
In the following, we will first present the background to this study, which includes the current controversy regarding the relative importance of economic, social and environmental motives in driving SMEs to integrate CSR into their business strategy. In this section, our hypotheses are presented. The methodology section explains our approaches to data collection and measurement. The French context is presented because we conduct our investigation among French SMEs. The remaining three sections cover the data analysis, interpretation of results, and conclusion.

\section{ECONOMIC, SOCIAL, AND ENVIRONMENTAL MOTIVES AS DRIVERS OF CSR INTEGRATION INTO SMES' BUSINESS STRATEGY: THE CONTROVERSY AND OUR HYPOTHESES}

\section{The Role of the Economic Motive}

Economic motive has been considered as an important driver of CSR integration into business strategy. It can be defined as the concern to economic viability of the firm, which is reflected in the way a firm operates in the market, moves beyond short-term profit maximizing issues to emphasize long-term economic performance issues, and exploits effectively market opportunities. Business owners of SMEs are increasingly positive about the business case for the integration of environmental and social measures into business strategy and operations. For example, research shows that many SMEs are clearly becoming more confident that being environmentally responsible can result in good publicity, which in turn may win customers and help to retain staff. They are also convinced that measures such as recycling and saving energy can help to reduce costs (Revell, Stokes, and Chen, 2010). Cultivating close relationships with workers and the social or business environment is expected to ensure collective action through increased confidence (Murillo and Lozano, 2006), more satisfaction among employees and an improvement in the company's image (Longo, Mura, and Bonoli, 2005). It is believed that an investment in social measures can pay off by rewarding SMEs with a framework for CSR that provides for mutual obligation, understanding and expectations that results in a 'win-win' strategy for all parties (Fisher et al., 2009).

Moreover, SMEs, anxious to survive, are driven by their customers to integrate social and environmental agenda into their business activities. Corporate customers and individual consumers are increasingly aware of social and environmental issues and start placing pressure upon SMEs. A host of 'willingness to pay' studies suggests that consumers across races (Newell and Green, 1997) and countries (Bhate, 2002) are willing to pay more for environmentally friendly products (Ottman, 1998). There is also an increasing take-up of ethical codes of practice by large business, which in turn creates a pressure for demonstrably responsible behavior back down the supply chain. For example, research carried out for the Department of Trade and Industry in the UK exploring the impact of CSR on SMEs found that most SMEs reported having to satisfy corporate customers regarding CSR issues $(60 \%$ on health and safety, $43 \%$ on environmental practices, $16 \%$ on social/ community commitment) (DTI, 2002).

Therefore, we predict that SMEs are driven by the economic motive to integrate CSR into their business strategy and operations.

Hypothesis 1: SMEs are driven by the economic motive to integrate CSR into their business strategy

\section{The Role of the Social Motive}

The current discussion related to the social motive of SMEs to integrate CSR into their business strategy and operations is divided. The social motive has the workplace and the community as two points of focus in creating social cohesion and equity. It recognizes 'the health, safety and general well-being of employees; motivate[s] the workforce by offering training and development opportunities; and enable[s] firms to act as good citizens in the local community' (European Commission, 2003b p. 5). Scholars have argued that SMEs have a true interest in caring for the community and the employees, which comes before their economic concerns. This is because the relationship between SMEs and the local authorities and employees is far closer and more direct than that of large business (Longo, Mura, and Bonoli, 2005). SMEs are particularly sensitive to the problems surrounding social responsibility: the entrepreneur 'experiences' in person, together with his family and his employees, the territory in which he operates, and shares with them both results and worries. Norms and pressures from employees, peer firms, and the community can drive SMEs to actively engage routinely in socially responsible behaviors (e.g. Arbuthnot, 
1997). Therefore, we hypothesize that the social motive comes before the economic one in motivating SMEs to engage in a strategic CSR behavior.

Hypothesis 2: The social motive plays a more important role than the economic motive in driving SMEs to integrate CSR into their business strategy.

However, scholars have argued that the social motive is not as important as the economic one in the SME context. Curran, Rutherfoord, and Lloyd-Smith (2000) indicated that small business owners tend to be detached from their locality, and from local economic initiatives, and cited historical trends that had reduced the role of small businesses in local political and economic processes as an explanation. Small businesses are often geographically isolated from the community in which they operate, situated on little-known industrial estates on the margins of towns and villages, and even those companies on large, highly visible estates are often over-shadowed by larger, well-known companies on those estates (Jenkins and Hines, 2002). The short-term nature of SMEs' strategy due to the survival pressure, financial resource limitations (Lepoutre \& Heene 2006; Sweeney 2007), reduced access to pools of human resources (De Kok \& Uhlaner, 2001), and less stakeholder pressure also mitigates against their commitment to social activities. SMEs may only be able to engage actively in a limited program of social-related CSR activities, or partly conduct such activities in isolation (Lepoutre and Heene, 2006). There is even a direct 'trade-off' among many SMEs between the contribution required to ensure the success of the business and the social and community contribution (GWE Research, 2007). When SMEs have an 'enlightened' stance towards their social responsibility, by 'putting something back' and being accountable to the community there is certainly a pragmatic aspect to this moral duty, and an element of 'self-interest', a central tenet of which is the idea of 'mutual benefit'. The companies recognize that communities that are invested in will prosper, and prosperous communities are good for business; a notion of 'shared' fate (Curran, Rutherfoord, and Lloyd-Smith, 2000). Thus, SMEs are more motivated by the economic motive than by the social motive in integrating CSR into their business strategy.

Hypothesis 3: The social motive plays a less important role than the economic motive in driving SMEs to integrate CSR into their business strategy.

\section{The Role Of The Environmental Motive}

The environmental motive can be broadly classified into two levels: reactive and proactive (Torugsa, O'Donohue, and Hecker, 2013). The reactive environmental motive is defined as concerns to protect the environment by complying with regulatory norms and standards. Companies aim at expending only the minimum level of effort required for regulatory compliance. Having the proactive environmental motive, firms aim at transforming their operational activities to achieve eco-efficiency and develop environmental-friendly products/services (Bos-Brouwers, 2010), thereby engaging above and beyond regulatory requirements.

It can be argued that many certification systems are difficult to administrate and organize for small businesses, institutional pressure often leads to environmental activities of mere compliance, which in turn have been found to have an insignificant impact on a firm's business activities (Darnall, Henriques, and Sadorsky, 2008). SMEs comply with environmental norms and standards because of the need for long-term survival and the license to operate. This level of commitment is linked to behaviors aimed at avoiding the negative consequences of noncompliance. It has been found that the types of environmental practices that produce a cost reduction effect, as well as being a positive change in environmental terms are those that tend to be most consistently applied by SME owner-managers (Ilomaki and Melanen, 2001). This points to an obvious conclusion: that it is the cost reduction element of the behavior change that is motivating, and the environmental benefit is simply a positive byproduct (Williamson, Lynch-Wood, and Ramsay, 2006). The implication being that if there was not a cost reduction benefit attached, the environmental dimension of the change in itself would not have been enough to stimulate a behavior change. Therefore, we predict that compared to the economic motive, the reactive environmental motive has a smaller influence in motivating SMEs to integrate CSR into their business strategy.

Hypothesis 4: The reactive environmental motive plays a less important role than the economic motive in driving SMEs to integrate CSR into their business strategy. 
On the other hand, it has been reported that SME managers are undergoing a steady improvement in their environmental awareness (e.g. Masurel, 2007; Vernon et al., 2003) and their concern about their environmental impact (e.g. Roberts, Lawson, and Nicholls, 2006; Tilley, 1999). Gadenne, Kennedy, and McKeiver (2009) go further to confirm that the majority of SME owner have a high level of awareness and a strong positive 'green' attitudes. For example, the Netregs survey of the UK's Environmental Agency found that SMEs are more likely to be motivated by environmental concerns and far less motivated by commercial benefits or legislative pressure. Many SMEs invest substantial resources in achieving eco-efficiency and developing green products/services without an expectation of return (Simpson, Taylor, and Barker, 2004). In this regard, environmental sustainability is seen as an integral part of their overall responsibility as business owners. The trend of for clean and green is growing very strong among SMEs. Thus, we argue that the proactive environmental motive plays a more important role than the economic ones in the adoption of strategic CSR behavior by SMEs.

Hypothesis 5: The proactive environmental motive plays a more important role than the economic motive in driving SMEs to integrate CSR into their business strategy.

\section{METHODOLOGY}

\section{The French Context}

Nations are different with regard to the CSR practices due to the economic conditions, the level of competition, and a variety of institutional conditions (Campbell, 2007). A growing body of evidence supports this argument. For example, Papasolomou-Doukakis, Krambia-Kapardis, and Katsioloudes (2005) found that the CSR approach of Cypriot businesses depends on the importance of managerial initiative, and financial gain is a key motive for the adoption of CSR by the business sector in Cyprus for tax deduction purposes. Maignan and Ralston (2002) examined public motive to socially responsible behavior study of firms in France, the Netherlands, the United Kingdom, and the United States. The fact that they found systematic differences in responses across the four countries suggests that nationally specific political, cultural, and other institutions may have been responsible.

France provides an interesting testing ground for our study. French SMEs are believed to adopt social and environmental measures and integrate them into business strategy and operations. A few studies in French SMEs found that the major driver of integrating CSR into business strategy is the beliefs and values of top managers, with economic motive coming in only the second place (Hudson and Roloff, 2010; Berger-Douce, 2008). However, the underlying motives that have been most commonly heard come from the government intervention. The French government particularly supports SMEs in their CSR activities. Since the execution of National Sustainable Development Strategy 2003-2008, public institutions have been active in financially supporting SMEs in pursuing CSR agenda. A number of projects have been carried out by regional authorities to assist local SMEs in integrating CSR into their operational and strategic activities. France is also well known for its strong protection of labor right. Whereas in English the term social includes society, in France it is focused internally on labor-related issues, rather than on external stakeholders. The influence from French labor law, the trade unions, and the long-standing mandatory social report has led to thorough application of the social side of CSR as far as employee treatment and rights are concerned (Antal and Sobczak, 2007). In terms of environmental issues, the focus on environmental aspect is considered as weaker in France in comparison with other European countries such as Germany and countries in Northern Europe (Hudson and Roloff, 2010). However, the media buzz around the "Grenelle law", introduced in 2009 and 2010 (www.legrenelle-environnement.gouv.fr), combined with general public education and access to the media who all carry the same message of urgency around environmental issues, helps improve environmental awareness and practices among French companies.

\section{Sample and Data Collection}

The sample for this study is drawn from a panel of about 1200 French SMEs, who are members of the Center for Young Entrepreneurs, a French association of SMEs. It should be noted that the term 'young entrepreneurs' does not indicate the members' age. There is no age limit to become members of the association. 
In collaboration with the Center, we conducted an online survey in 2011 about their CSR practices. There were 21 questions for the purpose of this study. These questions are part of 100 questions aiming at examining to what extent the members engaged with CSR in a strategic manner. These 100 questions were first developed started in 2002, they were then revised several times base on pilot studies and feedback from participating members, and were finally approved by enterprises participating in pilot studies. Due to the particular characteristic of SMEs that owners control everything (Spence, 1999), respondents of this research project were owners of the participating SMEs. The 21 questions can be divided into four sets, covering the following elements:

- Set 1: Economic motive. It is composed of 5 questions related to growth plan, definition of strategy, evolution of strategy, market watch, and profitability.

- Set 2: Social motive. Contains 4 questions addressing working condition, social dialogue, diversity, and human rights.

- Set 3: Reactive environmental motive. It contains 3 questions related to carbon release, environmental norms and standards, and resources for environmental protection.

- Set 4: Proactive environmental motive. It includes 2 questions related to environmental impact analysis, environmental-friendly products/services

- Set 5: Integration of CSR into business strategy. It has 7 questions related to participation of stakeholders in defining strategy, CSR in vision of the firm, balancing between economic, social, and environmental activities, CSR in performance indicator, quality of product/service, choice of suppliers, and CSR obligation of suppliers.

For each of these questions, there are four levels of answer: no commitment or minimum motive required by the law (score 1), active plan and actions to be made in the short term (score 2), active plan and actions (score 3), and aspirations for ideals (score 4). The final sample includes then 155 SMEs that responded to all of these 21 questions.

These levels of answer were inspired from the model of Enderle and Tavis (1998) and Enderle (2004), which distinguishes three levels of CSR motive: minimal ethical requirements, positive obligations beyond the minimum, and aspiration for ethical ideals. Score 4 corresponds to the highest level: aspirations for ethical ideals; score 3 corresponds to the level of positive obligations beyond the minimum; scores 1 and 2 correspond to the level of minimal ethical requirements. We had two scores corresponding the lowest level of engagement because the authors did not provide a detailed definition about 'minimum ethical requirements', acknowledging that the contents of these basic norms have to be specified at a more concrete level. They suggested to consider these requirements as generally accepted norms in the society, such as not to kill, not to deceit, not to rob, and not to exploit. As SMEs are likely to perceive that CSR is an issue that only pertains to larger firms (Vives, 2006; Sweeney, 2007), score 1 was added to take into account the possibility that SMEs may not necessarily feel concerned about the CSR issues. Score 2 signifies that they are following minimal ethical requirements but plan to undertake active engagement in CSR.

\section{Statistical Method}

We use a hierarchical multiple regression analysis to examine the comparative roles of the economic, social, reactive environmental motives, and proactive environmental motive in leading to the integration of CSR into business strategy. In our analysis, the independent variables are the economic, social, reactive environmental motives, and the proactive environmental motive. They are measured by the questions in Set 1, Set 2, Set 3, and Set 4 , respectively. The dependent variable is the adoption of a holistic approach towards CSR. It is measured by the questions in Set 5 .

The control variables include firm size and tangibility of sector. Firm size is a control variable because within the category of small firms, firms are heterogeneous in terms of size. It is measured as the number of people employed by the firm in 2011. We then recode this variable as an ordinal variable according to our size categories. SMEs having less than ten employees were coded as 1, from 10 to 49 employees as 2, from 50 to 99 as 3 , and from 100 to 249 as 4 . 
Tangibility of sector is also a control variable because it has been shown to motivate the active engagement in CSR practices of the SMEs (e.g. Uhlaner et al., 2012; Jenkins, 2006; Graafland, van de Ven, and Stofelle, 2003). To measure tangibility of sector, the sample firms are first grouped into nine sectors, including manufacturing, construction, transport and communication, retail and repair, catering and hospitality, agriculture, financial services, business services, and other services. The variable is then recoded as an ordinal variable according to the degree of tangibility, as proposed by Uhlaner et al. (2012). Firms in financial services, business services and other service sectors are coded as intangible services (1). Firms in transport and communication, retail and repair, and catering and hospitality are coded as tangible services (2). Firms in manufacturing, construction and agriculture are coded as tangible products (3).

\section{DATA ANALYSIS}

\section{Internal Consistency Reliability}

The economic, social, reactive environmental motives, and the proactive environmental motive are our independent variables. The values of Cronbach's $\alpha$ of the items measuring these variables are $0.74,0.66,0.67$ and 0.82 , respectively. The integration of CSR into business strategy is our dependent variable. The value of Cronbach's $\alpha$ of the items measuring this variable is 0.69 .

\section{Common-Method Bias Test}

Table 1 presents the results of the common method bias test for the items included in the scales measuring our independent variables.

As factor loadings indicate the strength of a relationship between an item and the factors, they provide conclusion whether the item should be included in the factor (Hair et al., 2006). Using the cut-off criterion of an eigenvalue greater than or equal to one, the Varimax rotated factor analysis presented in Table 1 provides a fourfactor solution, including economic motive, social motive, reactive environmental motive, and proactive environmental motive. As can be seen in Table 1, the intended factor loadings of individual items range from 0.53 to 0.86 , which are above the recommended minimum of $|0.5|$ (Hair et al., 2006). The unintended loadings are very low, with only one factor loading being at 0.47 . In the unrotated solution, the total solution explains $60.93 \%$ of the variance, with the first factor explaining $33 \%$ of the variance. These findings support the assumption that these variables measure different constructs and reduce the likelihood that common method bias is a problem in this study (Podsakoff and Organ, 1986).

Table 1. Common Method Bias Test: Factor Loading From Principal Component Analysis, Rotated Solution

\begin{tabular}{|c|c|c|c|c|}
\hline Variable & $\begin{array}{c}\text { Reactive } \\
\text { environnemental motive }\end{array}$ & $\begin{array}{c}\text { Economic } \\
\text { motive }\end{array}$ & Social motive & $\begin{array}{c}\text { Proactive } \\
\text { environmental motive }\end{array}$ \\
\hline Growth plan & 0.18 & 0.66 & 0.06 & 0.14 \\
\hline Definition of strategy & 0.05 & 0.72 & 0.31 & -0.16 \\
\hline Evolution of strategy & 0.08 & 0.60 & 0.23 & 0.37 \\
\hline Market watch & 0.31 & 0.70 & -0.00 & 0.15 \\
\hline Profitability & -0.04 & 0.58 & 0.13 & 0.21 \\
\hline Working condition & 0.13 & 0.14 & 0.74 & 0.18 \\
\hline Social dialog & 0.11 & 0.28 & 0.67 & -0.01 \\
\hline Diversity & 0.27 & 0.11 & 0.67 & 0.01 \\
\hline Human rights & 0.03 & -0.04 & 0.53 & 0.47 \\
\hline Environmental impact analysis & 0.27 & 0.08 & 0.09 & 0.77 \\
\hline Environmental-friendly products/services & 0.33 & 0.14 & 0.04 & 0.71 \\
\hline Carbon release & 0.82 & 0.10 & 0.06 & 0.13 \\
\hline Environmental norms and standards & 0.77 & 0.14 & 0.14 & 0.28 \\
\hline Resources for environmental protection & 0.86 & 0.08 & 0.14 & 0.12 \\
\hline
\end{tabular}




\section{Description Of Bivariate Statistics}

Table 2 reports the bivariate Pearson-correlation coefficients between the variables included in the study. These statistics provides preliminary answers to our research question. The pattern of correlation coefficients listed in the table shows that the integration of CSR into business strategy is dependent upon the economic and social motives, to the proactive environmental motive, and to the reactive environmental motive.

It can be seen from Table 2 that the largest positive correlation is observed between the integration of CSR into business strategy and the economic motive, where $r=0.72(p<0.05)$. The second largest correlation $(r=0.52$, $p<0.05$ ) is between the social motive and the integration of CSR into business strategy. It is followed by the relationship with the proactive environmental motive and the reactive environmental motive. The $r$ values are 0.41 and $0.42(p<0.05)$, respectively.

In addition, firm size is correlated with the integration of CSR into business strategy $(r=0.33, p<0.05)$ and sector tangibility $(r=0.19, p<0.05)$, but not other variables. The tangibility of sector correlation is also not significant with any variables.

Table 2. Bivariate Correlations Between Variables

\begin{tabular}{|c|c|c|c|c|c|c|c|}
\hline Variable & 1 & 2 & 3 & 4 & 5 & 6 & 7 \\
\hline 1. Integration of CSR into business strategy & 1.0000 & & & & & & \\
\hline 2. Firm size & $\begin{array}{l}0.3321 * \\
0.0000 \\
\end{array}$ & 1.0000 & & & & & \\
\hline 3. Sector tangibility & $\begin{array}{l}0.0944 \\
0.2428 \\
\end{array}$ & $\begin{array}{l}0.1990^{*} \\
0.0131 \\
\end{array}$ & 1.0000 & & & & \\
\hline 4. Economic motive & $\begin{array}{l}0.7224 * \\
0.0000 \\
\end{array}$ & $\begin{array}{l}0.2591 * \\
0.0011 \\
\end{array}$ & $\begin{array}{l}0.0863 \\
0.2858 \\
\end{array}$ & 1.0000 & & & \\
\hline 5. Social motive & $\begin{array}{l}0.5285^{*} \\
0.0000 \\
\end{array}$ & $\begin{array}{l}0.3086^{*} \\
0.0001 \\
\end{array}$ & $\begin{array}{l}0.0445 \\
0.5821 \\
\end{array}$ & $\begin{array}{l}0.4358^{*} \\
0.0000 \\
\end{array}$ & 1.0000 & & \\
\hline 6. Proactive environmental motive & $\begin{array}{l}0.4181 * \\
0.0000\end{array}$ & $\begin{array}{l}0.1385 \\
0.0857 \\
\end{array}$ & $\begin{array}{l}0.0946 \\
0.2415 \\
\end{array}$ & $\begin{array}{l}0.3519^{*} \\
0.0000 \\
\end{array}$ & $\begin{array}{l}0.3501 * \\
0.0000 \\
\end{array}$ & 1.0000 & \\
\hline 7. Reactive environmental motive & $\begin{array}{l}0.4266^{*} \\
0.0000\end{array}$ & $\begin{array}{l}0.2855^{*} \\
0.0003\end{array}$ & $\begin{array}{l}0.0122 \\
0.8801\end{array}$ & $\begin{array}{l}0.3844 * \\
0.0000\end{array}$ & $\begin{array}{l}0.3883^{*} \\
0.0000\end{array}$ & $\begin{array}{l}0.5176^{*} \\
0.0000\end{array}$ & 1.0000 \\
\hline
\end{tabular}

$(*) p<0.05$

\section{Multiple Regression Analysis}

Our multiple regression analysis corresponds to ordinary least squares hierarchical multiple regression techniques. The variables are entered into the model in blocks. The first block includes only control variables. In following analysis, each independent variable is entered alternatively in two different regression analyzes - as second and last block, respectively. The significance of the change in $\mathrm{R}$ squared $\left(\Delta R^{2}\right)$ in the second block provides an initial indication of answer for the hypotheses. More robust support is found for those variables when there is additional significant variance of the $\Delta R^{2}$ in the final block of the model. Two-way interaction effects are also tested for all combination of the three independent variables. A test for multicollinearity is included for each multiple regression analysis using variance inflation factor (VIF) score (Hair et al., 2006). A test for the existence of the matrix $\left(X^{\mathrm{T}} X\right)^{-1}$ is also made. 
Table 3. Comparative Influence of Economic Motive, Social Motive, Proactive Environmental Motive, And Reactive Environmental Motive in Driving SMEs to Integrate CSR Into Business Strategy

\begin{tabular}{|c|c|c|c|}
\hline \multirow{2}{*}{ Variables } & \multirow{2}{*}{ Full model } & \multicolumn{2}{|c|}{$\Delta R^{2}$ when variable entered in Model } \\
\hline & & After controls & Last in the model \\
\hline Constant & 0.40 & & \\
\hline Firm size & $0.68^{\mathrm{a}}$ & & \\
\hline Sector tangibility & 0.004 & & \\
\hline Economic motive & $0.45^{b}$ & $0.43^{\mathrm{c}}$ & $0.23^{\mathrm{c}}$ \\
\hline Social motive & $0.17^{b}$ & $0.20^{\mathrm{c}}$ & $0.03^{\mathrm{c}}$ \\
\hline Proactive environmental motive & $\mathbf{0 . 0 8 5}^{\mathrm{a}}$ & $0.14^{\mathrm{c}}$ & $0.015^{\mathrm{b}}$ \\
\hline Reactive environmental motive & 0.038 & & \\
\hline Adjusted $R^{2}$ & $0.59^{\mathrm{c}}$ & & \\
\hline$F(\mathrm{df} 1, \mathrm{df} 2)$ & 37.76 & & \\
\hline
\end{tabular}

Table 3 presents the results of the multiple regression analysis describing the relationship between the integration of CSR into business strategy and the economic motive, the social motive, the proactive environmental motive, and the environmental compliance, while controlling for firm size and sector tangibility. The variables are free from multicollinearity since the VIF scores are all well below the recommended cut-off of 10 (Hair et al., 2006). The matrix $\left(X^{\mathrm{T}} X\right)^{-1}$ also exists, which confirms the non-dependence of any pair of variables.

It can be seen from Table 3 that firm size and sector tangibility do not influence the integration of CSR into business strategy (the test is not significant at the level of 0.05 ). The all-variable model explains $59 \%$ of the variance in the prediction of the integration of CSR into business strategy $(F=37.76, p<0.05)$.

Significant regression coefficients are found for three of the four independent variables: the economic motive, the social motive and the proactive environmental motive. The two columns on the far right of Table 3 report the proportion of variation of the dependent variable that is explained by each of the independent variables. The column labeled 'after controls' presents the results when the variables are each added individually in a second block immediately following control variables. The column labeled 'last variable in the model' provides results when the variables are added individually as the last block in the model.

Hypothesis 1 predicts that SMEs are driven by the economic motive to integrate CSR into business strategy. It is supported by result related to the variable of economic motive. The economic motive explains about $43 \%$ of variation in the dependent variable when added immediately following controls $\left(\Delta R^{2}=0.43, p<0.001\right)$ and $23 \%$ of the variation when added as a last block in the full model $\left(\Delta R^{2}=0.23, p<0.001\right)$.

Hypothesis 2 states that the social motive is more important than the economic one in motivating SMEs to integrate CSR into business strategy, while hypothesis 3 claims the opposite prediction. The result related to the variable of social motive rejects hypothesis 2 and supports hypothesis 3 . The social motive explains $20 \%$ of variation in the dependent variable when added immediately following controls $\left(\Delta R^{2}=0.20, p<0.001\right)$ and $3 \%$ of the variation when added as a last block in the full model $\left(\Delta R^{2}=0.03, p<0.001\right)$. Thus, the economic motive plays a more important role than the social motive in SMEs' strategic CSR behavior.

Hypothesis 4 predicts that the reactive the environmental motive is less important than the economic one in motivating SMEs to integrate CSR into business strategy, while hypothesis 5 has the opposite prediction for the proactive environmental motive. The relationship between the reactive environmental motive and the integration of CSR into business strategy by SMEs is not significant. The reactive environmental motive does not motivate SMEs to integrate CSR into business strategy. Hypothesis 4 is supported. The proactive environmental motive explains $14 \%$ of variation in the dependent variable when added immediately following controls $\left(\Delta R^{2}=0.14, p<0.001\right)$ and $1.5 \%$ of the variation when added as a last block in the full model $\left(\Delta R^{2}=0.013, p<0.1\right)$. Thus, hypothesis 5 is rejected. 


\section{INTERPRETATION OF RESULTS}

From our analysis, some important findings can be highlighted. First, the economic motive has the highest level of influence in driving French SMEs to integrate CSR into their business strategy. The social motive comes in the second place. The reactive environmental motive does not have any impact. However, the influence of the social motive is indirect. The significant drop in variance explained by the social motive indicates that its effect may not be direct, being mediated by the variable of economic motive. $\Delta R^{2}$ drops significantly when these variables are added last in the model. Their impact is mediated by the economic motive. This implies that the economic motive is the main driver of integrating CSR into business strategy. The concerns for economic survival prevail over the concerns to protect the environment and address employee and community issues. The environmental and social behavior in itself is not sufficient to motivate French SMEs to integrate CSR issues into their business strategy and operations.

Second, it is important to note that among the environmental measures, only the proactive environmental motive, which implies the degree to which the firm transforms its business activities and operations to protect the environment, plays a role. We do not find the impact of the reactive environmental motive. The different impact of the two types of environmental motive can be explained by their nature. The practice of proactively protecting the environment can potentially lead to competitive advantage through green product development (Orsato, 2006). The reactive environmental motive is required by the regulation and does not necessarily create competitive advantage. The different impact of the two types of environmental motive implies that firms have different attitudes toward normative-oriented and the strategic-oriented environmental practices. This finding is in line with the discussion of Williamson, Lynch-Wood, and Ramsay (2006) about regulation and business performance motives of environmental behavior of SMEs. It also confirms one more time the finding that the economic motive is more important than the social and environmental ones with regard to CSR practices adopted by French SMEs.

The results of our investigation are different from current studies what have been found among medium firms. Lamberti and Noci (2012), from their study of a medium Italian company, claimed that it was the ethical motivations that had encouraged a more strategic approach to CSR at first, then the positive outcomes of the initiatives have reinforced the CEO's belief in the effectiveness of a strategic approach to CSR. Preuss and Perschke (2010) shared similar finding about a medium firm, which does not care only about profit but show genuine concerns for people. This supports the argument that CSR practices differ within the SME sector. However, in our regression analysis, firm size, as a control variable, does not influence the integration of CSR into business strategy. This means that within the SME sector, companies are homogeneous in terms of CSR behavior.

Our study makes several contributions to the understanding of SME behavior in adopting a holistic approach towards CSR. First, it compares the roles of economic, social, and environmental motives in influencing French SMEs to integrate CSR into business strategy, showing that the economic motive is the most important factor. Second, the concern to maintain economic objectives does not mean social and environmental motives are forgotten. It rather facilitates the influence of social and environmental motives on the adoption of holistic CSR. These two contributions are in line with the argument of Avram and Kuhne (2008) that if SMEs become aware of their position within their industry, they have a better starting position when it comes to identifying social and environmental issues that will enhance their strategic positioning or even lever a possible growth path. Finally, complying with environmental legislation does motivate SMEs to integrate CSR into business strategy. This is because such commitment does not require firms to go beyond regulation compliance to regulations, which are commonly considered as having negative impact on business competitiveness (cf. SBS, 2004). It has been pointed out by Jenkins (2004) that the emphasis on formal systems and standard setting of CSR will undermine the effort in implementing CSR of SMEs.

\section{PRACTICAL IMPLICATIONS}

With these findings, implications of our research are as following. To promote a strategic CSR behavior among SMEs, the business case is appropriate. This is an important implication because it supports the European Commission's view that self-regulation is the most appropriate mechanism for stimulating CSR (European Commission, 2001). Although the economic motive prevails over the desire to protect the environment and the society, it serves as mediators to integrate environmental and social issues into business strategy and operations. 
SMEs can do well by doing good to the environment, the employees, and the society they operate in. Importantly, to facilitate CSR integration into business strategy, the government needs to go further than imposing on them the standard environmental practices such as environmental norms. They need to be committed to proactively protect the environment. Such commitment may include changes in the development of products and services.

\section{CONCLUSION}

In conclusion, our study has identified comparative roles of the economic, social, and environmental motives in motivating SMEs to integrate CSR into business strategy. It is found that when they committed to ensure economic performance, they are most motivated to follow this approach. The economic motive also facilitates the role of social and environmental ones. Depending on the environmental measures to which they are committed, they may or may not integrate CSR into their business strategy and operations. We contribute to opening the black box of the relationship between CSR and business strategy in SMEs (cf. Perrini and Minoja, 2008).

This study has some limitations. The respondents of the survey are all members of the Center for Young Entrepreneurs, who are traditionally active in implementing CSR. They may have some characteristics that nonmembers do not, leading to some degree of bias in the results. Moreover, the study is conducted in a particular national context. Thus, we suggest that in future research the same study should be replicated on a larger scale in France or in other countries, so that our results can be generalized. We also suggest that qualitative studies should be conducted to examine in better depth the integration of CSR into business strategy and operations. As our study showed that firm size has an impact on the CSR behavior, an investigation comparing small and medium firms in terms of CSR integration into business strategy would reveal interesting insights.

\section{AUTHOR INFORMATION}

Linh-Chi Vo is an Associate Professor at Normandy Business School. Her research interest includes Corporate Social Responsibility, gender diversity, and innovation.

Karen Delchet-Cochet is an Associate Professor in Corporate Social Responsibility at ISC Paris since 2010 and is the head of Management and Information Systems Department. She obtained her doctorate degree in Environmental Science at Ecole des Mines de Saint Etienne, France in March 2006.

Hakim Akeb is an Associate Professor in Computer Science and Data Analysis at ISC Paris Business School since 2007. He obtained his doctorate degree in Computer Science at University of Picardie Jules Verne, Amiens, France in December 2005.

\section{REFERENCES}

Antal, A. B., \& Sobczak, A. (2007). Corporate Social Responsibility in France; A Mix of National Traditions and International Influence. Business \& Society, 46(1), 9-32.

Arbuthnot, J. J. (1997). Identifying ethical problems confronting small retail buyers during the merchandise buying processs. Journal of Business Ethics, 16, 745-755.

Avram, D., \& Kuhne, S. (2008). Implementing Responsible Business Behavior from a Strategic Management Perspective: Developing a Framework for Austrian SMEs. Journal of Business Ethics, 82, 463-475.

Berger-Douce, S. (2008). Rentabilité et pratiques de RSE en milieu PME. Premiers résultats d'une étude française. Management et Avenir, 15, 9-29.

Bhate, S. (2002). One world, one environment, one vision: are we close to achieving this? An exploratory study of consumer environmental behaviour across three countries. Journal of Consumer Behaviour, 2(2), 169-184.

Bos-Brouwers, H. E. (2010). Corporate sustainability and innovation in SMEs: evidence of themes and activities in practice. Business Strategy and the Environment, 19(7), 417-435.

Campbell, J. (2007). Why would corporations behave in socially responsible ways? An institutional theory of corporate social responsibility. Academy of Management Review, 32, 946-967.

Curran, J., Rutherfoord, R., \& Lloyd-Smith, S. (2000). Is There a Local Business Community? Explaining the NonParticipation of Small Business in Local Economic Development. Local Economy, 15( 2), 128-143. 
Darnall, N., Henriques, I., \& Sadorsky, P. (2008). Do environmental management systems improve business performance in an international setting? Journal of International Management, 14, 364-376.

de Kok, J., \& Uhlaner, L. (2001). Organization context and human resource management in the small firm. Small Business Economics, 17(4), 273-291.

DTI. (2002). Engaging SMEs in community and social issues. London: DTI.

European Commission. (2001). Promoting a European Framework for Corporate Social Responsibility. Green Paper (Com 366, July), Luxembourg: Office for Official Publications of the European Communities.

European Commission. (2003b). Responsible entrepreneurship: A collection of good practice cases among small and medium- sized enterprises across Europe. Bruxelles: Belgium.

Enderle, G., \& Travis, L. A. (1998). A Balanced Concept of the Firm and the Measurement of Its Long-Term Planning and Performance. Journal of Business Ethics, 17(11), 1129-1144.

Enderle, G. (2004). Global competition and corporate responsibilities of small and medium-sized enterprises. Business Ethics: A European Review, 13(1), 51-63.

Fisher, K., Geenen, J., Jurcevic, M., McClintock, K., \& Davis, G. (2009). Applying asset-based community development as a strategy for CSR: a Canadian perspective on a win-win for stakeholders and SMEs. Business Ethics: A European Review, 18, 66-84.

Gadenne, D., Kennedy, J., \& McKeiver, C. (2009). An empirical study of environmental awareness and practices in SMEs. Journal of Business Ethics, 84(1), 45-63.

Graafland, J., van de Ven, B., \& Stofelle, N. (2003). Strategies and instruments for organizing CSR by small and large businesses in the Netherlands. Journal of Business Ethics, 47, 45-60.

GWE Research. (2007). Thames Valley Area programme: SME Social and Community Responsibility. Midsomer Norton: GWE Research.

Hair, F., Black, W., Babin, B., Anderson, R., \& Tatham, R. (2006). Multivariate data analysis (6th ed.). Upper Saddle River, NJ: Prentice Hall.

Hudson, S., \& Roloff, J. (2010). In search of sustainability? SMEs in Britanny, France. in Spence, L. and PainterMorland, M. (Eds.) Ethics in small and medium sized enterprises: a global commentary. Dordrecht, Netherlands: Springer.

Ilomaki, M., \& Melanen, M. (2001). Waste minimisation in small and medium-sized enterprises - do environmental management systems help? Journal of Cleaner Production, 9, 209-217.

Jenkins, H. (2004). A critique of conventional CSR theory: An SME perspective. Journal of General Management, 29(4), 37-57.

Jenkins, H. (2006). Small business champions for corporate social responsibility. Journal of Business Ethics, 67 , 241-256.

Jenkins, H., \& Hines, F. (2002). Shouldering the burden of corporate social responsibility: what makes business get committed? $10^{\text {th }}$ International Conference of the Greening of Industry Network, Gothenburg, Sweden, 2326 June 2002.

Lamberti, L., \& Noci, G. (2012). The relationship between CSR and corporate strategy in medium-sized companies: evidence from Italy. Business Ethics: A European Review, 21( 4), 402-416.

Lepoutre, J., \& Heene, A. (2006). Investigating the impact of firm size on small business social responsibility: A critical review. Journal of Business Ethics, 67, 257-273.

Longo, M., Mura, M., \& Bonoli, A. (2005). Corporate social responsibility and corporate performance: the case of Italian SMEs. Corporate Governance, 5, 28-43.

Maignan, I., \& Ralston, D. (2002). Corporate social responsibility in Europe and the U.S.: Insights from businesses' self-presentations. Journal of International Business Studies, 33, 497-514.

Masurel, E. (2007). Why SMEs invest in environmental measures: sustainability evidence from small and mediumsized printing firms. Business Strategy and the Environment, 16( 3), 190-201.

Morsing, M., \& Perrini, F. (2009). CSR in SMEs: do SMEs matter for the CSR agenda? Business Ethics: A European Review, 18(1), 1-6.

Murillo, D., \& Lozano, J. (2006). SMEs and CSR: An approach to CSR in their own words. Journal of Business Ethics, 67, 227-240.

Newell, S., \& Green, C. (1997). Racial differences in consumer environmental concern. The Journal of Consumer Affairs, 31(1), 53-69.

Orsato, R. (2006). Competitive environmental strategies: When does it pay to be green? California Management Review, 48, 127-145. 
Ottman, J. (1998). Green Marketing: Opportunity for Innovation. Chicago, IL: NTC.

Papasolomou-Doukakis, I., Krambia-Kapardis, M., \& Katsioloudes, M. (2005). Corporate Social Responsibility: The Way Forward? Maybe Not. European Business Review, 17(3), 263-279.

Perrini, F., \& Minoja, M. (2008). Strategizing corporate social responsibility: evidence from an Italian mediumsized, family-owned company. Business Ethics: A European Review, 17(1), 47-63.

Porter, M., \& Kramer, M. 2002. The Competitive Advantage of Corporate Philanthropy. Harvard Business Review, $80(12), 56-68$.

Podsakoff, P., \& Organ, D. (1986). Self-reports in organizational research: Problems and prospects. Journal of Management, 12(4), 531-544.

Preuss, L., \& Perschke, J. (2010). Slipstreaming the Larger Boats: Social Responsibility in Medium-Sized Businesses. Journal of Business Ethics, 92(4), 531-551.

Revell, A., Stokes, D., \& Chen, H. (2010). Small business and the environment: turning over a new leaf? Business strategy and the environment, 19, 273-288.

Roberts, S., Lawson, R., \& Nicholls, J. (2006). Generating Regional-Scale Improvements in SME Corporate Responsibility Performance: Lessons from Responsibility Northwest. Journal of Business Ethics, 67, 275286.

SBS - Small Business Service. (2004). A government plan for Small Business: Evidence Base (Small Business Service, London). Retreived from http://www.sbs.gov.uk/SBS_Gov_files/corporateinfo/sbs_evidence.pdf.

Simpson, M., Taylor, N., \& Barker, K. (2004). Environmental responsibility in SMEs: does it deliver competitive advantage? Business Strategy and the Environment, 13, 156-171.

Spence, J. J. (1999). Does size matter? The state of the art in small business ethics. Business Ethics: A European Review, 8(3), 163-174.

Sweeney, L. (2007). Corporate social responsibility in Ireland: Barriers and opportunities experienced by SMEs when undertaking CSR. Corporate Governance, 7(4), 516-523.

Tilley, F. (1999). The gap between the environmental attitudes and the environmental behaviour of small firms. Business Strategy and the Environment, 8, 238-248.

Torugsa, N., O'Donohue, W., \& Hecker, R. (2013). Proactive CSR : An empirical analysis of the role of its economic, social and environmental dimensions on the association between capabilities and performance. Journal of Business Ethics, 115, 383-402.

Ulhaner, L., Berent-Braun, M., Jeurissen, R., \& de Wit, G. (2012). Beyond Size: Predicting Engagement in Environmental Management Practices of Dutch SMEs. Journal of Business Ethics, 109, 411-429.

Vernon, J., Essex, S., Pinder, D., \& Curry, K. (2003). The 'greening' of tourism micro-businesses: outcomes of focus group investigations in South East Cornwall. Business Strategy and the Environment, 12, 49-69.

Vives, A. (2006). Social and environmental responsibility in small and medium enterprises in Latin America. Journal of Corporate Citizenship, 21, 39-50.

Williamson, D., Lynch-Wood, G, \& Ramsay, J. (2006). Drivers of environmental behavior in manufacturing SMEs and the implications for CSR. Journal of Business Ethics, 67, 317-330. 